\title{
Effect of Palliative Educational Program on Nurses Knowledge and Skills among Advanced Cancer Patients
}

\begin{abstract}
Rabab Mahmoud Moneir ${ }^{1}$, Galila El Ganzory ${ }^{2}$, Rania Abdelhamed ${ }^{3}$ and Faten Mohamed Ahmed $^{4}$

(1)Assist.lecturer of Psychiatric-Mental Health Nursing at El-glaa Institute, (2) Professor of Psychiatric-Mental Health Nursing, Faculty of Nursing, Ain Shams University, Egypt ,(3) Assist professor of Psychiatric-Mental Health Nursing, Faculty of Nursing, Ain Shams University and (4) Assist professor of Psychiatric-Mental Health Nursing, Faculty of Nursing, Benha University, Egypt.
\end{abstract}

\begin{abstract}
Background: Comprehensive cancer care requires the integration of palliative care practices and principles across the trajectory of the cancer experience and may be the sole focus of care for those patients with advanced incurable disease. Aim of the study: This study aimed to determine the effect of palliative educational program on nurse's knowledge and skills among advanced cancer patients. Research design: A quasi-experimental was used in the study. Setting: This study was conducted at the inpatients oncology departments and out patients of palliative clinics at Nasser Institute, the hospital affiliated to the ministry of health. Sample: Convenience sample of 40 staff nurses caring patients in the end stage of cancer or have metastatic cancer were included in this study. Tools of data collection: Part I. Socio- demographic data. Part II. Assessment tool for nurses' knowledge about palliative care for advanced cancer patients, nurses' knowledge regarding pain management of palliative care for advanced cancer patients, nurses' knowledge regarding relative's role of palliative care for advanced cancer patients and nurses' nursing care for palliative care for advanced cancer patients Results: the main results revealed an increase knowledge satisfactory $67.5 \%$ post implemented palliative educational program. Conclusion: There was need for continuing education for upgrading nurse' knowledge about palliative care. Recommendations: Enrichment of all nurses at any educational institute about knowledge and skills related to palliative care according to the standard guidelines will be helpful to achieve quality of life. Also are that due attention should be given towards PC by the national health policy and needs to be incorporated in the national curriculum of nurse education.
\end{abstract}

\section{Key words: Palliative Care, Cancer Patients, Nurses' Knowledge, Nurses’ Practice.}

\section{Introduction}

Palliative Care (PC) is an approach that improves the quality of life for patient and their families facing problem associated whit chronic serious illness (WHO 2015). PC is considered as one of the most important aspect for patients' care at the end stage of life. It provides the patients with comfort and decreases the period of suffering from illness. So world today concerns its interests toward practice of palliative care for patients with end stage of life to alleviate the symptoms of disease and ensure about peace death (Kumar, 2010).

The World Health Organization defined the palliative care as "an approach which improves the patients' quality of life and their families 
that facing life-threatening problems through prevention and relief of suffering by early detection, pain management and assessment of physical, psychosocial and spiritual problems" (WHO, 2014).

So, the palliative care contains integrated multidisciplinary collaboration between the patients, their families, health professionals and the public toward a continuum of care confirming on physical, mental, social, spiritual and emotional dimensions of care for lifelimiting or life- threatening conditions (Çevik, 2018).

The goal of palliative care is not to cure, but to provide comfort and reach the highest possible quality of life for individuals suffering from severe lace in different environments of palliative care and at any situation (Kassa, 2014). There is confusion between palliative care and end of life care, where the first refers specifically to care provided in the last phase of life which often defined as approximately the last year. But end of life care sometimes refers to the last weeks or even days of life and can include care into bereavement (Grubb, 2016).

Education and training of palliative care influences not only the level of care provided but also the level of team participation of the healthcare professionals, where the knowledge of nurses influences the quality of care provided to these patients (Elshamy, 2015).

Palliative care clinical nurse specialists play an important role in providing the palliative care to patients, where they spend more time with patients and their families, helping them come to terms with an array of complex emotional and practical problems, facilitating communication, giving information and advice about treatments and also offering expertise in controlling pain and other distressing symptoms these nurses are equipped with specialist skills to assess the complex palliative care needs of patients referred to the service (Harazneh, 2015).

\section{Significance of the study}

Because the nursing schools give limited emphasis for palliative care in the educational curriculum plan, in clinical areas and the incidence of death patients increase each year with no developing to palliative care, it is necessary to conduct our study to evaluate the effect of palliative care educational program on nursing about their knowledge and Skills toward care of dying (Saylor, 2016).

The complexity and nature of care required for palliative care patients can be a stressor to nurses and can pose a threat when working with palliative care patients. Due to the complexity of palliative care, nurses are often unprepared to care for patients with terminal or chronic, serious illness. The lack of proper training and education in palliative care nursing can create negative attitudes that can impact care outcomes.

\section{Aim of the study}

The study aimed to determine the effect of palliative educational program on nurse's knowledge and skills among advanced cancer patients.

\section{Hypothesis:}

Nurses' knowledge and skills among advanced cancer patients will show better enhancement after implementing of palliative educational program. Including criteria -Age-both sex willing and accept to participate.

\section{Subjects and Method}

\section{Research design:}

The present study was use a quasiexperimental research design to evaluate the 
effect of palliative educational Program on nurse's knowledge and skills among advanced cancer Patients.

\section{Setting:}

The study was conducted in the inpatients oncology departments and out patients of palliative clinics at Nasser Institute, The hospital affiliated to the ministry of health.

\section{Sampling:}

A sample of convenience of 40 staff nurses caring patients in the end stage of cancer or have metastatic cancer were included in this study. They are recruited over the period of 1 "st January 2020 to June month according to the previously mentioned setting, They agreed to participate in the study, filled in the data collection tools.

\section{Inclusion criteria:}

- Willing to participate.

- Aged 20-50

- Male and female

- Different educational levels

Tools of data collection: Tools were used to collect the data through:

First tool: A structured Interviewing this tool was designed by the researcher and written in simple Arabic language based on scientific literature review to gather data in relation to the following parts:

Part I. Socio demographic data included age, occupation, education, department and years of experience and attended training courses.

Part II. Nurses' knowledge about palliative care for cancer patient (50 questions), including: nurses' knowledge regarding concept of palliative care for cancer patient (18 true/false questions), nurses' knowledge regarding pain management of palliative care for cancer patient (11 true/false questions), nurses' knowledge regarding relatives role of palliative care for cancer patient (6 true/false questions), nurses' nursing care for palliative care for cancer patient (15 true/false questions).

Scoring system: The right answer was scored one, and that wrong was scored zero. These scores were summed-up and converted into a percent score: score ranged from $<32.5$ referred to unsatisfactory knowledge and score ranged from 67.5 to $\leq 100$ referred to satisfactory knowledge.

\section{The palliative educational program:}

Actual study divided into four phases:

\section{A) Assessment phase:}

Include comprehensive assessment of the study sample, knowledge and skills in relation to advanced cancer patients and palliative care.

\section{B) Planning phase:}

Planning and designing phase of program will be developed by the researcher including objectives, content, skills, methodology, timing and place, afterward it will be revised by experts in the psychiatric mental and health nursing field as a jury to ensure content validity.

\section{C) Implementation phase:}

In this phase the researcher will carry out the health educational program of nurse's knowledge and skills among advanced cancer patients and palliative care.

\section{D) Evaluation phase:}

The evaluation of the implemented program will be done by reapplying of 
structured interview schedule, Assessment nurses' knowledge and skills questionnaire on the experimental group immediately after implantation of the program.

\section{Content validity and reliability:}

To achieve the criteria of trust worthiness of the tools of data collection in this study, it was tested and evaluated for face and content validity by 5 expertise in psychiatric mental health from faculty members from Ain Shams University to ascertain relevance, clarity, and completeness of the tools, experts elicited responses that either agree or disagree for the face and content validity. While validity score of tools is (0.922 and 0.912) for nurse's knowledge and skills respectively, this indicated high total internal consistency of the used tool.

\section{Ethical considerations:}

The researcher was clarified the objective and aimed of the program to the nurses included in the study, Anonymity and confidentiality of the data was being assured and maintained, Nurses was being informed that they are allowed to participate or not in the study and that they have the right to withdraw from the study at any time.

\section{Pilot study:}

The Pilot study will be carried out for $10 \%$ of the sample to clarification and test the reliability and applicability of the tools, then the tools will be modified according to the finding of pilot study.

\section{Field work:}

To carry out the study, an approval was obtained from the dean of faculty of nursing
Benha University, a letter containing the title and aim will be directed to the hospital director and head manger of oncology department at Nasser institute. Explaining the aim of the study in order to obtain their permission and cooperation. Data collection lasted for 6 months. The researcher will be available two days / week (Saturday and Tuesday from $12 \mathrm{pm}$ to $1 \mathrm{pm})$. All nurses was interviewed individually using the previously mentioned study tools. The time consumed to fill out the full questionnaire ranged from 20 to 30 minutes for one questionnaire depending on the response of the participants. The researcher first met with the nurses exposed to palliative patient in the previously mentioned setting, explained the purpose of the study after introducing herself. The nurses were assured that information collected would be treated confidentially, and it would be used only for the purpose of the research. Then, individual interviewing was done after obtaining nurses consent to participate.

\section{Statistical analysis:}

Data collected from the studied sample was revised, coded and entered using PC. Computerized data entry and statistical analysis were fulfilled using the statistical package for social sciences (SPSS) version 20. Data were presented using descriptive statistics in the form of frequencies, percentages. Chi-square test(X2) was used for comparisons between qualitative variables and correlation sufficiency was used to test correlation between variables. Statistical significant was considered at p-value $<0.05$. 


\section{Results:}

Table (1) showed that, $65 \%$ of the studied nurses were between ages of $31 \leq 40$ years old with mean age of $37.2 \pm 2.3,65 \%$ of them were female and $62.5 \%$ of them lives in rural areas, while $52.5 \%$ were married, $40 \%$ of them were technical institute, and $(67.5 \%)$ of them mentioned their monthly income not enough.

Table (2) clarified that, $47.5 \%, 45 \%, 35 \%$, $47.5 \%$ and $30 \%$ ) of the studied nurses had incorrect answer about palliative care is appropriate only in situations where there is evidence of a downhill trajectory or deterioration, the accumulation of losses renders burnout inevitable for those who seek work in palliative care, the loss of a distant or contentious relationship is easier to resolve than the loss of one that is close or intimate, during the terminal stages of an illness, drugs that can cause respiratory depression are appropriate for the treatment for severe dyspnea and men generally reconcile their grief more quickly than women respectively pre intervention program compared to $57.2 \%, 52.5 \%, 72.5 \%, 60 \%$ and $60 \%$ of the studied nurses had correct answer post intervention program with statistically significant difference between nurses knowledge about knowledge about concept of palliative care throughout the intervention program $(\mathrm{p}<0.05)$.

Table (3) clarified that, $37.5 \%, 35 \%, 30 \%$ and $42.5 \%$ of the studied nurses had incorrect answer about the extent of the disease determines the method of pain treatment, adjuvant therapies are important in managing pain, the pain threshold is lowered by anxiety or fatigue and it is appropriate to control pain in the dying phase by use of both analgesia and sedation respectively pre intervention program compared to $57.2 \%, 62.5 \%$,
$57.5 \%$ and $70 \%$ of the studied nurses had correct answer post intervention program with statistically significant differences between nurses knowledge about pain assessment for palliative patient throughout the intervention program $(\mathrm{p}<0.05)$.

Table (4) clarified that, $32.5 \%, 47.5 \%$, $37.5 \%$ and $45 \%$ of the studied nurses had incorrect answer about the morphine is the standard used to compare the analgesic effect of other opioids, Demerol is not an effective analgesic in the control of chronic pain, in high doses, codeine causes more nausea and vomiting than morphine and individuals who are taking opioids should also follow a bowel regime respectively pre intervention program compared to $55 \%, 55 \%, 62.5 \%$ and $62.5 \%$ of the studied nurses had correct answer post intervention program with highly statistically significant difference between nurses knowledge about pain management for palliative patient throughout the intervention program $(\mathrm{p}<0.01)$.

Table (5) clarified that, $47.5 \%$ and $37.5 \%$ of the studied nurses had incorrect answer about the effort to make the last days tolerable for relatives was sufficient and affirmation of the patient as a whole person was sufficient respectively pre intervention program compared to $67.5 \%$ and $65 \%$ of the studied nurses had correct answer post intervention program with highly statistically significant difference between nurses knowledge about communication with relative and palliative patient throughout the intervention program $(\mathrm{p}<0.01)$. 
Table 1: Percentage distribution of the studied nurses according to their socio-demographic characteristic

\begin{tabular}{|c|c|c|}
\hline Items & No & $\%$ \\
\hline \multicolumn{3}{|l|}{ Age } \\
\hline $20 \leq 30$ years & 6 & 15.0 \\
\hline $31 \leq 40$ years & 26 & 65.0 \\
\hline $41 \leq 50$ years & 8 & 20.0 \\
\hline Mean \pm SD & 37 & $2 \pm 2.3$ \\
\hline \multicolumn{3}{|l|}{ Gender } \\
\hline Nale & 14 & 35.0 \\
\hline Female & 26 & 65.0 \\
\hline \multicolumn{3}{|c|}{ Residence } \\
\hline$\overline{\text { Urban }}$ & 15 & 37.5 \\
\hline Rural & 25 & 62.5 \\
\hline \multicolumn{3}{|c|}{ Marital status } \\
\hline Single & 10 & 25.0 \\
\hline Married & 21 & 52.5 \\
\hline Divorced & 5 & 12.5 \\
\hline Widow & 4 & 10.0 \\
\hline \multicolumn{3}{|c|}{ Oualification } \\
\hline Diploma murse & 10 & 27.5 \\
\hline Technical institute & 16 & 40.0 \\
\hline Bachelor & 8 & 20.0 \\
\hline Master degree & 5 & 12.5 \\
\hline \multicolumn{3}{|c|}{ Monthly income } \\
\hline Enough & 13 & 32.5 \\
\hline Not emough & 27 & 67.5 \\
\hline
\end{tabular}


Table 2: Distribution of the studied nurses according to their knowledge about concept of palliative care throughout the intervention program

\begin{tabular}{|c|c|c|c|c|c|c|c|c|c|c|c|c|}
\hline \multirow{3}{*}{ Concept of palliative care } & \multicolumn{5}{|c|}{ Pre } & \multicolumn{5}{|c|}{ Post } & \multirow{3}{*}{$\mathrm{X} 2$} & \multirow{3}{*}{$\begin{array}{c}\mathrm{P} \\
\text { Value }\end{array}$} \\
\hline & True & \multicolumn{2}{|c|}{ False } & \multicolumn{2}{|c|}{$\begin{array}{l}\text { Don't } \\
\text { Know }\end{array}$} & True & \multicolumn{2}{|c|}{ False } & \multicolumn{2}{|c|}{$\begin{array}{l}\text { Don't } \\
\text { Know }\end{array}$} & & \\
\hline & \begin{tabular}{|l|l|} 
No & $\%$ \\
\end{tabular} & No & $\%$ & No & $\%$ & \begin{tabular}{|l|l|} 
No & $\%$ \\
\end{tabular} & & $\%$ & No & $\%$ & & \\
\hline $\begin{array}{l}\text { Palliative care is appropriate only } \\
\text { in situations where there is } \\
\text { evidence of a downhill trajectory or } \\
\text { deterioration }\end{array}$ & \begin{tabular}{l|l}
11 & 27.5
\end{tabular} & 19 & 47.5 & 10 & 25.0 & $23 \mid 57.5$ & 9 & 22.5 & 8 & 20.0 & 8.02 & 0.01 \\
\hline $\begin{array}{c}\text { The accumulation of losses renders } \\
\text { bumout inevitable for those who } \\
\text { seek work in palliative care } \\
\end{array}$ & 1230.0 & 18 & 45.0 & 10 & 25.0 & $21 \mid 52.5$ & 13 & 32.5 & 6 & 15.0 & 4.26 & 0.12 \\
\hline $\begin{array}{c}\text { An acute episode in a chronically ill } \\
\text { patient may represent a terminal } \\
\text { event }\end{array}$ & 1025.0 & 16 & 40.0 & 14 & 35.0 & $21 \mid 52.5$ & 12 & 30.0 & 7 & 17.5 & 6.80 & 0.03 \\
\hline $\begin{array}{c}\text { The loss of a distant or contentious } \\
\text { relationship is easier to resolve than } \\
\text { the loss of one that is close or } \\
\text { intimate }\end{array}$ & 1640.0 & 14 & 35.0 & 10 & 25.0 & 2972.5 & 7 & 17.5 & 4 & 10.0 & 8.66 & 0.01 \\
\hline $\begin{array}{c}\text { The decision that a patient is dying } \\
\text { should be made by a } \\
\text { multidisciplinary team }\end{array}$ & 1127.5 & 15 & 37.5 & 14 & 35.0 & $21 \mid 52.5$ & 11 & $27.5 \mid$ & 8 & 20.0 & 5.37 & 0.06 \\
\hline $\begin{array}{l}\text { The provision of palliative care } \\
\text { requires emotional detachment }\end{array}$ & $9|22.5|$ & 15 & 37.5 & 16 & 40.0 & 2050.0 & 9 & 22.5 & 11 & 27.5 & 6.59 & 0.03 \\
\hline $\begin{array}{l}\text { During the terminal stages of an } \\
\text { illness, drugs that can cause } \\
\text { respiratory depression are } \\
\text { appropriate for the treatment for } \\
\text { severe dyspnea }\end{array}$ & 820.0 & 19 & 47.5 & 13 & 32.5 & 2460.0 & 10 & 25.0 & 6 & 15.0 & 13.37 & 0.001 \\
\hline $\begin{array}{c}\text { Men generally reconcile their grief } \\
\text { more quickly than women }\end{array}$ & \begin{tabular}{|l|l|l|}
12 & 30.0
\end{tabular} & 12 & 30.0 & 16 & 40.0 & 2460.0 & 11 & $27.5 \mid$ & 5 & 12.5 & 9.80 & 0.007 \\
\hline $\begin{array}{l}\text { The dying person should not be } \\
\text { allowed to make decisions about } \\
\text { physical care }\end{array}$ & 1435.0 & 11 & 27.5 & 15 & 37.5 & $20 \mid 50.0$ & 12 & 30.0 & 8 & 20.0 & 3.23 & 0.19 \\
\hline Total mean score & \begin{tabular}{|l|l|}
11 & 27.5 \\
\end{tabular} & 15 & 37.5 & 14 & 35.0 & \begin{tabular}{|l|l|}
23 & 57.5 \\
\end{tabular} & 11 & 27.5 & 6 & 15.0 & 8.05 & 0.01 \\
\hline
\end{tabular}


Table 3: Distribution of the studied nurses according to their knowledge about pain assessment for palliative patient throughout the intervention program

\begin{tabular}{|c|c|c|c|c|c|c|c|c|c|c|c|c|c|c|}
\hline \multirow{3}{*}{ Pain assessment } & \multicolumn{6}{|c|}{ Pre } & \multicolumn{6}{|c|}{ Post } & \multirow{3}{*}{$\mathrm{X} 2$} & \multirow{3}{*}{ P Value } \\
\hline & \multicolumn{2}{|c|}{ True } & \multicolumn{2}{|c|}{ False } & \multicolumn{2}{|c|}{$\begin{array}{l}\text { Don't } \\
\text { Know }\end{array}$} & \multicolumn{2}{|c|}{ True } & \multicolumn{2}{|c|}{ False } & \multicolumn{2}{|c|}{$\begin{array}{l}\text { Don't } \\
\text { Know }\end{array}$} & & \\
\hline & No & $\%$ & No & $\%$ & No & $\%$ & No & $\%$ & No & $\%$ & No & $\%$ & & \\
\hline $\begin{array}{c}\text { Manifestations of } \\
\text { chronic pain are } \\
\text { different from those } \\
\text { of acute pain }\end{array}$ & 9 & 22.5 & 20 & 50.0 & 11 & 27.5 & 21 & 52.5 & 13 & 32.5 & 6 & 15.0 & 7.75 & 0.02 \\
\hline $\begin{array}{c}\text { The extent of the } \\
\text { disease determines } \\
\text { the method of pain } \\
\text { treatment }\end{array}$ & 12 & 30.0 & 15 & 37.5 & 13 & 32.5 & 23 & $\mathbf{5 7 . 5}$ & 10 & 25.0 & 7 & 17.5 & 6.25 & 0.04 \\
\hline $\begin{array}{c}\text { Adjuvant therapies } \\
\text { are important in } \\
\text { managing pain } \\
\end{array}$ & 11 & 27.5 & 14 & 35.0 & 15 & 37.5 & 25 & 62.5 & 9 & 22.5 & 6 & 15.0 & 10.38 & 0.01 \\
\hline $\begin{array}{c}\text { The pain threshold } \\
\text { is lowered by } \\
\text { anxiety or fatigue }\end{array}$ & 18 & 45.0 & 12 & 30.0 & 10 & 25.0 & 23 & $\mathbf{5 7 . 5}$ & 9 & 22.5 & 8 & 20.0 & 1.26 & 0.53 \\
\hline $\begin{array}{l}\text { It is appropriate to } \\
\text { control pain in the } \\
\text { dying phase by use } \\
\text { of both analgesia } \\
\text { and sedation }\end{array}$ & 15 & 37.5 & 17 & 42.5 & 8 & 20.0 & 28 & 70.0 & 7 & 17.5 & 5 & 12.5 & 8.78 & 0.01 \\
\hline Total mean score & 12 & 30.0 & 16 & 40.0 & 12 & 30.0 & 24 & 60.0 & 10 & 25.0 & 6 & 15.0 & 7.38 & 0.02 \\
\hline
\end{tabular}


Table 4: Distribution of the studied nurses according to their knowledge about pain management for palliative patient throughout the intervention program

\begin{tabular}{|c|c|c|c|c|c|c|c|c|c|c|c|c|c|c|}
\hline \multirow{3}{*}{ Pain management } & \multicolumn{6}{|c|}{ Pre } & \multicolumn{6}{|c|}{ Post } & \multirow{3}{*}{$\mathbf{X} 2$} & \multirow{3}{*}{$\begin{array}{c}\mathbf{P} \\
\text { Value }\end{array}$} \\
\hline & \multicolumn{2}{|c|}{ True } & \multicolumn{2}{|c|}{ False } & \multicolumn{2}{|c|}{$\begin{array}{l}\text { Don't } \\
\text { Know }\end{array}$} & \multicolumn{2}{|c|}{ True } & \multicolumn{2}{|c|}{ False } & \multicolumn{2}{|c|}{$\begin{array}{l}\text { Don't } \\
\text { Know }\end{array}$} & & \\
\hline & No & $\%$ & No & $\%$ & No & $\%$ & No & $\%$ & No & $\%$ & No & $\%$ & & \\
\hline $\begin{array}{l}\text { Morphine is the standard used to compare } \\
\text { the analgesic effect of other opioids }\end{array}$ & 7 & 17.5 & 13 & 32.5 & 20 & 50.0 & 22 & 55.0 & 12 & 30.0 & 6 & 15.0 & 15.33 & 0.0004 \\
\hline $\begin{array}{l}\text { The use of placebos is appropriate in the } \\
\text { treatment of some types of pain }\end{array}$ & 9 & 22.5 & 13 & 32.5 & 18 & 45.0 & 21 & 52.5 & 11 & 27.5 & 8 & 20.0 & 8.81 & 0.01 \\
\hline $\begin{array}{l}\text { Demerol is not an effective analgesic in the } \\
\text { control of chronic pain }\end{array}$ & 8 & 20.0 & 19 & 47.5 & 13 & 32.5 & 22 & 55.0 & 7 & 17.5 & 11 & 27.5 & 12.23 & 002 \\
\hline $\begin{array}{l}\text { In high doses, codeine causes more nausea } \\
\text { and vomiting than morphine }\end{array}$ & 11 & 27.5 & 15 & 37.5 & 14 & 35.0 & 25 & 62.5 & 8 & 20.0 & 7 & 17.5 & 9.91 & 0.007 \\
\hline $\begin{array}{l}\text { Individuals who are taking opioids should } \\
\text { also follow a bowel regime }\end{array}$ & 10 & 25.0 & 18 & 45.0 & 12 & 30.0 & 25 & 62.5 & 6 & 15.0 & 9 & 22.5 & 12.85 & 0.001 \\
\hline $\begin{array}{l}\text { Drug addiction is a major problem when } \\
\text { morphine is used on a long-term basis for } \\
\text { the management of pain }\end{array}$ & 11 & 27.5 & 13 & 32.5 & 16 & 40.0 & 19 & 47.5 & 12 & 30.0 & 9 & 22.5 & 4.13 & 0.12 \\
\hline $\begin{array}{l}\text { Use of opioids is appropriate to control pain } \\
\text { for the dying patient }\end{array}$ & 12 & 30.0 & 10 & 25.0 & 18 & 45.0 & 21 & 52.5 & 9 & 22.5 & 10 & 25.0 & 4.79 & 0.09 \\
\hline Total mean score & 10 & 25.0 & 14 & 35.0 & 16 & 40.0 & 22 & 55.0 & 9 & 22.5 & 9 & 22.5 & 7.54 & 0.02 \\
\hline
\end{tabular}

Table 5: Distribution of the studied Nurses according to their knowledge about communication with relative and palliative patient throughout the intervention program

\begin{tabular}{|c|c|c|c|c|c|c|c|c|c|c|c|c|c|c|}
\hline \multirow{3}{*}{$\begin{array}{c}\text { Communication with relative and } \\
\text { palliative patient }\end{array}$} & \multicolumn{6}{|c|}{ Pre } & \multicolumn{6}{|c|}{ Post } & \multirow{3}{*}{$\mathrm{X} 2$} & \multirow{3}{*}{$\begin{array}{c}\mathbf{P} \\
\text { Value }\end{array}$} \\
\hline & \multicolumn{2}{|c|}{ True } & \multicolumn{2}{|c|}{ False } & \multicolumn{2}{|c|}{$\begin{array}{l}\text { Don't } \\
\text { Know }\end{array}$} & \multicolumn{2}{|c|}{ True } & \multicolumn{2}{|c|}{ False } & \multicolumn{2}{|c|}{$\begin{array}{l}\text { Don't } \\
\text { Know } \\
\end{array}$} & & \\
\hline & No & $\%$ & No & $\%$ & No & $\%$ & No & $\%$ & No & $\%$ & & $\%$ & & \\
\hline $\begin{array}{r}\text { Effort to } \mathrm{n} \\
\mathrm{re}\end{array}$ & 12 & 30.0 & 19 & 47.5 & 9 & 22.5 & 27 & 67.5 & 8 & 20.0 & 5 & 12.5 & 11.39 & 0.003 \\
\hline $\begin{array}{r}\text { Relative } \mathrm{k} \\
\text { situ }\end{array}$ & 9 & 5 & 13 & 32.5 & 18 & 45.0 & 23 & 57.5 & 9 & 22.5 & 8 & 20.0 & 0.69 & C \\
\hline & 7 & 17.5 & 18 & 45.0 & 15 & 37.5 & 23 & 57.5 & 10 & 25.0 & 7 & 17.5 & 13.72 & 0.001 \\
\hline $\begin{array}{r}\text { Affirmat } \\
\mathrm{p}\end{array}$ & 3 & 5 & 15 & 37.5 & 12 & 30.0 & 26 & .0 & 8 & 20.0 & 6 & 15.0 & 8.46 & 0.01 \\
\hline $\begin{array}{l}\text { Attention to } \\
\text { of patien }\end{array}$ & 18 & 45.0 & 12 & 30.0 & 10 & 25.0 & 23 & 57.5 & 9 & 22.5 & 8 & 20.0 & 1.26 & 0.5 \\
\hline $\begin{array}{r}\text { It is cru } \\
\text { at }\end{array}$ & 11 & 27.5 & 19 & 47.5 & 10 & 25.0 & 23 & 57.5 & 12 & 30.0 & 5 & 12.5 & 7.48 & 0.02 \\
\hline Total mea & 12 & 30.0 & 16 & 40.0 & 12 & 30.0 & 24 & 60.0 & 9 & 22.5 & 7 & 17.5 & 8.27 & 0.01 \\
\hline
\end{tabular}




\section{Discussion}

Nurses spend more time with patients and families than any other health professional as they face serious illness. Expert nursing care reduces the distress and burdens of those facing death, and the ability to offer support for unique physical, social, psychological, and spiritual needs of the patients and their families. Palliative care can be provided concurrently with curative measures (Teklay et al., 2020). Concurrent care is different than a traditional hospice model, where curative therapy, or life extending measures such as palliative chemotherapy, generally have ceased. Palliative care nurses have adjusted their frame of mind from one which revolves around specific tasks such as vital signs, treatments, and interventions, to one of comfort, symptom management, and support (Kurnia et al., 2019).

This study aimed to evaluate the effect of palliative educational program on nurse's knowledge and skills among advanced cancer patients.

Concerning the personal characteristics of the studied nurses, the current study revealed that, about two thirds of the studied nurses their age were between $31 \leq 40$ years old with mean age of $37.2 \pm 2.3$, almost two thirds of them were female and less than two thirds of them lives in rural areas, while more than half are married, two fifths of them had technical institute, and two thirds of them mentioned their monthly income not enough. These results were in agreement with the result of Kim et al., (2020), studied the Knowledge, attitude and self-efficacy towards palliative care among nurses in Mongolia and found that, the median age was 37.5 years, the majority of them were women, three quarters of the nurses had a bachelor's degree, about two thirds of them were married and more than half of them were from rural areas.

A similar results observed in a study with Hassan et al., (2016), studied the Knowledge and practices of critical care nurses regarding palliative care of cancer patients and suggestion for nursing guidelines booklet and found that, the majority of studied nurses were at the age group between 20 to 40 years, females, and married, nursing diploma is the highest proportion, and more than half of nurses had years of experiences about 5 years and more.

This could be due to that, the majority of nurses were females that may be due to nursing school science along time were receive female more than male student.

Concerning the years of experience of the studied nurses, the current study revealed that, more than half of them have experience between 11-15 years. The result of the present study was following Kim et al., (2020), studied the Knowledge, attitude and self-efficacy towards palliative care among nurses in Mongolia and reported that, the median total years of nursing experience was ten years, while the median years of oncology nursing experience was seven years.

Concerning the knowledge of the studied nurses regarding palliative care throughout the intervention program, the current study revealed that, more than one quarter of the studied nurses had correct answer about concept of palliative care during preintervention program compared to more than half of the studied nurses had correct answer during post intervention program. This result was supported by a study done by Teklay et al., (2020), who found that, the majority of the 
respondents knew the definition of $\mathrm{PC}$ and agreed that PC is being given when patient's conditions are downhill trajectory or deterioration.

This result was in agreement with Mohamed et al., (2017), studied the impact of palliative care program on nurse's knowledge and practice regarding care of patients with end-stage renal disease and revealed that, the most of study subjects had unsatisfactory knowledge level in preprogram phase, while the most of them in post program phase and the majority of them in follow up phase had satisfactory knowledge level. This result was in agreement with the result of Hassan et al., (2016), and mentioned that, the majority of studied nurses had unsatisfactory knowledge scores regarding total items of palliative care.

This could be due to that these nurses have not been trained on palliative care, limited attention to nurses' continuing education.

This may be due to that the nurses usually well concerned with obey command of doctor especially giving medication and neglected their nursing role as assessment of pain and non-pharmacological management of pain.

This could be due to that, the lack of protocols and basic standard guidelines on pain assessment and management for palliative patient and nurses working with no specialization.

Concerning the nurse's knowledge about signs \& symptoms during dying process throughout the intervention program, the current study revealed that, one third of the studied nurses had correct answer about signs \& symptoms during dying process during preintervention program compared to less than two thirds of the studied nurses had correct answer during post intervention program. Finding of current study agree with Pai \& Ongole, (2015) revealed that, majority of the staff nurses had satisfactory knowledge scores about Psychological issues that is may be due to the experiences and seniority nurses or they consider their work with cancer patients as meaningful and rewarding.

The current finding supported with Iranmanesh, et al., (2014) found that the lowest correct answers were in the category of spiritual care. Approximately the same finding was indicated by Morsy et al., (2014) who found that, the majority of the studied sample had unsatisfactory general knowledge; and unsatisfactory knowledge about physical symptoms requiring palliative care. However, they had satisfactory knowledge about psychological symptoms. This results was in agreement with Iranmanesh, et al., (2014) found that, the most correct answers were in the category of management of pain and other symptoms less than half and the lowest correct answers were in the category of psychosocial care.

According nurse's knowledge about nursing management for palliative patient throughout the intervention program, the current study revealed that, less than one third of the studied nurses had correct answer about nursing management for palliative patient during pre-intervention program compared to more than half of the studied nurses had correct answer during post intervention program. The current finding supported with Alshaikh et al., (2015), studied the nurses' knowledge about palliative care in an intensive care unit in Saudi Arabia and found that, a highly significant difference in nurses' knowledge of palliative 
care nursing after a brief palliative nursing education.

According nurse's total knowledge regarding palliative care throughout the intervention program, the current study revealed that, two fifths of the studied nurses had correct answer about total knowledge regarding palliative care during pre-intervention program compared to more than two thirds of the studied nurses had correct answer during post intervention program with statistically significant difference between the studied nurses regarding their total knowledge regarding palliative care throughout the intervention. This result was in agreement with the result of Kurnia et al., (2019), studied the factors associated with nurses' self-efficacy in applying palliative care in intensive care unit and found that, the median palliative care for nursing knowledge was lower.

These results were in the same line with a study done by Metwaly, (2020), studied the medical surgical nursing, department of medical surgical nursing, faculty of nursing, Zagazig University and reported that, nurses' practice level improved in the post-program phase. Most studied nurses had satisfactory level of practice regarding management of breathing difficulties, gastrointestinal symptoms, and management of itching after program implementation. Moreover, more than three-quarters of the studied nurses had satisfactory level of practice regarding management of fatigue after program, with highly statistically significant difference.

This may be due to the, the capacity to behave and perform actions with full understanding is acquired through learning, practice, and interaction with environments.
Concerning nurse's practice regarding care of patients with acute and / or chronic pain throughout the intervention program, the current study revealed that, one quarter of the studied nurses were incompetent practice regarding care of patients with acute and / or chronic pain during pre-intervention program compared to more than half of the studied nurses were competent practice during post intervention program. The current finding supported with Saylor et al., (2016), reported that, after a palliative care simulation education there was a significant improvement in building nurses' knowledge and skills related to palliative care. Specifically, the knowledge of Morphine as a standard to use for comparing the analgesic effect of other opioids indicated a highly statistically significant difference in the pre-post education intervention in this study.

According nurse's practice regarding care of patients with emergency throughout the intervention program, the current study revealed that, more than one quarter of the studied nurses were incompetent nurse's practice regarding care of patients with emergency during pre-intervention program compared to more than two thirds of the studied nurses were competent practice during post intervention program. The current finding supported with Kurnia et al., (2019), who studied the factors associated with nurses' selfefficacy in applying palliative care in intensive care unit and reported that, the majority of the studied nurses had total satisfactory level of practice after the program. However, the majority of studied nurses had satisfactory level of practice regarding management of breathing difficulties and gastrointestinal symptoms after the program. 
Concerning nurse's practice regarding psychosocial care throughout the intervention program, the current study revealed that, one third of the studied nurses were incompetent nurse's practice regarding psychosocial care during pre-intervention program compared to more than half of the studied nurses were competent practice during post intervention program. This result was consistent with Mohamed et al., (2017), clarified that, the studied nurses had unsatisfactory level of practice in preprogram phase.

This finding may be indicated that continuous education in nursing is needed to promote development of knowledge, skills, and attitudes of nurses and to improve the quality of care given for this group of patients.

According Practices of the studied nurses according to their total regarding palliative care throughout the intervention program, the current study revealed that, less half of the studied nurses were incompetent total practices regarding palliative care during pre-intervention program compared to more than two thirds of the studied nurses were competent during post intervention program with statistically significant difference between the studied nurses regarding their total practices regarding palliative care throughout the intervention. This result was consistent with Hassan et al., (2016), found that, more than half of studied nurses had unsatisfactory level of total practices score regarding palliative care of cancer patients that may be due to that nurses didn't receive definite training program about different aspect of palliative care the majority of studied nurses had unsatisfactory level of practice.
These results were in the same line with a study done by Metwaly, (2020), who studied the medical surgical nursing, department of medical surgical nursing, faculty of nursing, Zagazig University and reported that, nurses' practice level improved in the post-program phase. Most studied nurses had satisfactory level of practice regarding management of breathing difficulties, gastrointestinal symptoms, and management of itching after program implementation. Moreover, more than three-quarters of the studied nurses had satisfactory level of practice regarding management of fatigue after program, with highly statistically significant difference.

Concerning Correlation between total knowledge of the studied and their total practices regarding palliative care throughout the intervention, the current study revealed that; there was statistically significant difference between the studied nurses regarding their total knowledge and total practices throughout the intervention throughout the intervention. These results were in the same line with a study done by Metwaly, (2020), who studied the medical surgical nursing, department of medical surgical nursing, faculty of nursing, Zagazig University and who found that, there was a strong positive correlation between total knowledge score and total practice score after program, with highly statistically significant difference.

However, This result in the same line with the study of Begum and Khanam (2015), mentioned that, the practice of palliative care was observed to be adequate in less than half, moderately adequate in less than half, and inadequate in less than ten percent. These results matched with the study of Hassan et al., (2016), who studied the Knowledge and 
practices of critical care nurses regarding palliative care of cancer patients and suggestion for nursing guidelines booklet and found that, there was no statistically significant relation between practices and knowledge level of studied nurses.

This may be attributed to the importance of effective training program for improving nurses' knowledge.

\section{Conclusion}

The present study concluded that, nurses at oncology departments of palliative clinics at Nasser Institute, had unsatisfactory knowledge and practice regarding palliative care which is considered as an important aspect of improving cancer patients' quality of life. The majority of the involved nurses conducted incomplete symptom assessment, nursing management and blindly followed doctors' orders. However, a minority assessed and provided the required nursing management, the nurses' knowledge in palliative care improved after a brief palliative care nursing education.

\section{Recommendation:}

- Enrichment of all nurses at any educational institute about knowledge and practices related to palliative care according to the standard guidelines will be helpful to achieve quality of life

- Attention should be given towards PC by the national health policy and needs to be incorporated in the national curriculum of nurse education.

-Developing in-service educational program and training program for updating nurse's knowledge and skills to make them highly competent in meeting needs of palliative patient's care.

\section{References}

Al Qadire M (2018). Doctor of Oncology and Palliative care Nursing, Faculty of Nursing, Al al-Bayt University, Jordan, Knowledge of palliative care: An online survey, Nurse Education Today, Available online 9 September 2013.

Alshaikh Z, Alkhodari M, Sormunen T, Hillerås P (2020). Nurses' knowledge about palliative care in an intensive care unit in Saudi Arabia. Middle East J Nurs 9:7-13.

Begum S, Khanam M (2015). Knowledge and practice of staff nurses on palliative care. IJHRMLP 01:41-45.

Behr DJ (2019). Evaluation of impact of endof-life nursing education consortium (Elnec) education on registered nurses, doctorate degree of nursing practice, Rueckert-Hartman College for Health Professions. Denver, USA: Regis University. 135.

Elshamy K (2020). Current Status of Palliative Care Nursing in Egypt: Clinical Implementation, Education and Research. Journal of Palliative Care \& Medicine,; S5:1.

Sadhu S, Salins NS, Kamath A (2015). Palliative care awareness among Indian undergraduate health care students: A needsassessment study to determine incorporation of palliative care education in undergraduate medical, nursing and allied health education. Indian journal of palliative care; 16(3):154.

Ayed A (2020). Knowledge and practice of nursing staff towards infection control measures in the Palestinian hospitals. 
Harazneh L, Ayed A, Fashafsheh I (2020). Knowledge of Palliative Care among Bachelors Nursing Students. Journal of Health Medicine and Nursing; 18:25-32.

Kim HS, Kim BH, Yu SJ, Kim S, Park SH, Choi S, Yung Y (2016). The effect of an endof-life nursing education consortium course on nurses' knowledge of hospice and palliative care in Korea. J Hosp Palliat Nurs 13:222-229.

Kim S, Lee K, Kim S (2020). Knowledge, attitude, confidence, and educational needs of palliative care in nurses caring for non-cancer patients: a cross-sectional, descriptive study. BMC Palliative Care; 19(1):1-4.

Kuebler K (2019). Implications for palliative care nursing education. Clinical Scholars Review; 5(2):86-90.

Saylor J, Graber JS (2019). Influence Through Lifelong Learning: Membership Engagement Advances the Nursing Profession.

Kumar S and Jim A (2015). Physical therapy in palliative care: from symptom control to quality of life- a critical review. Indian J Palliat Care; 16:156-64.

Mohamed AA, Taha NM, Abd-Elaziz M, Abd- Elaziz EM (2017). Impact of Palliative Care Program on Nurse's Knowledge and practice regarding care of patients with endstage renal disease. Zagazig Nurs J 13:275-289. 


\section{تأثير برنامج تعليمى ملطّف على معرفة ومهارات الممرضات لاى مرضى السرطان المتقدمين} رباب محمود منير - جليلة الجنزوري - رانيا عبد الحميد ـ فاتن محم احمد في

يعد السرطان مشكلة عالمية ودولية و هو السبب الرئيسي الثناني للوفاة في جميع أنحاء العالم بعد أمر اض القلب

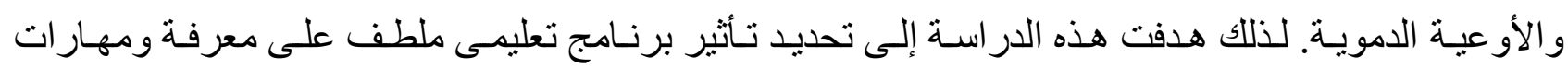

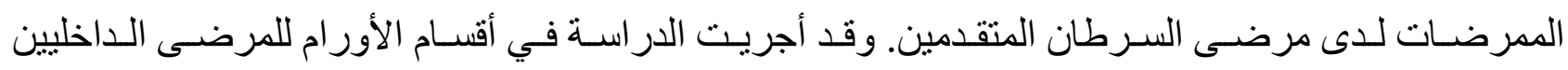

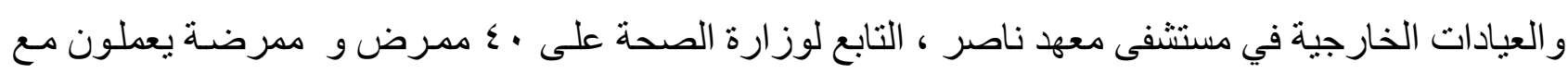

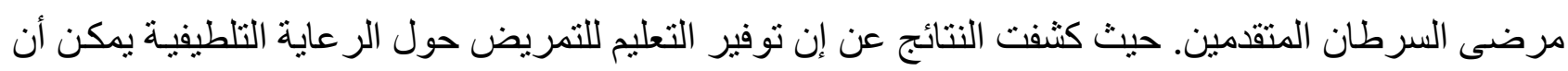

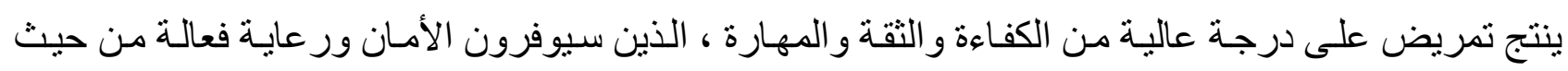

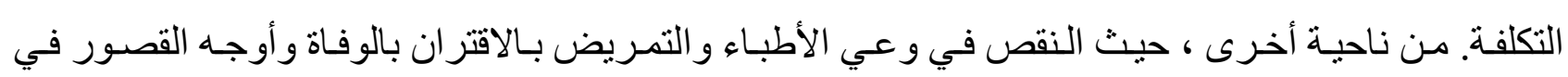

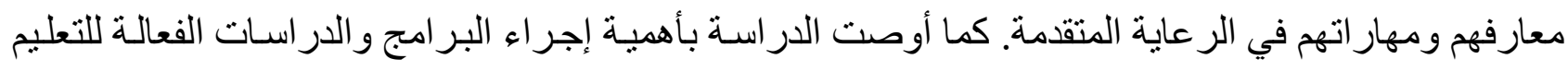

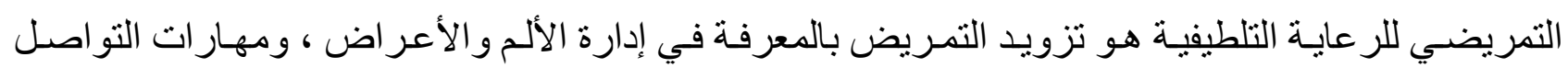
ولمناقثة أهداف الر عاية وقضايا نهاية العمر مع المرضى و العائلات مما لها نأثنير إيجابي على نو نو عية حياتهم. 